\title{
Combined Effects of Temperature and Salinity on Hatching and Larval Survival of Commercially Important Tropical Sea urchin, Tripneustes gratilla (Linnaeus, 1758)
}

\author{
Md. Shamim Parvez ${ }^{1}$, M. Aminur Rahman ${ }^{2,3^{*}}$, Md. Jahidul Hasan ${ }^{4}$, \\ Md. Habibur Rahman ${ }^{2}$, Nawshin Farjana ${ }^{2}$, Md. Habibur Rahman Molla \\ and Sang-Go Lee ${ }^{3}$ \\ ${ }^{1}$ Earth Solution Ltd., House \# 33, Road \# 4, Dhanmondi, Dhaka-1209, Bangladesh. \\ ${ }^{2}$ Department of Fisheries and Marine Bioscience, Faculty of Biological Science and Technology, \\ Jashore University of Science and Technology, Jashore-7408, Bangladesh. \\ ${ }^{3}$ World Fisheries University Pilot Programme, Pukyong National University (PKNU), 365 Sinseon-ro, \\ Nam-gu, Busan-48547, South Korea. \\ ${ }^{4}$ Department of Fisheries, Fish Inspection and Quality Control, Matshaya Bhaban, Boyara, \\ Khulna-9200, Bangladesh. \\ ${ }^{5}$ Department of Biology, Faculty of Science, King Abdulaziz University, Jeddah-21589, \\ Kingdom of Saudi Arabia. \\ Authors' contributions \\ The work was carried out in collaboration among all authors. All authors read, reviewed and approved \\ the final manuscript. \\ Article Information \\ DOI: $10.9734 / A R R B / 2020 / v 35 i 530219$ \\ Editor(s): \\ (1) Dr. Viduranga Y. Waisundara, Australian College of Business \& Technology, Sri Lanka. \\ Reviewers: \\ (1) Fernando Ariel Genta, Oswaldo Cruz Institute, Brazil. \\ (2) Guilherme de Souza Moura, Federal Univesity of Jequitinhonha an Mucuri Valleys, Brazil. \\ (3) Dayamon D. Mathew, Banaras Hindu University, India. \\ Complete Peer review History: http://www.sdiarticle4.com/review-history/57654
}

Original Research Article

Received 22 March 2020

Accepted 30 May 2020

Published 16 June 2020

ABSTRACT

The combined effects of temperature and salinity on percent hatching, normal larval rate at hatching, and survival of fasting larvae after hatching (survival activity index; SAI) of the commercial species of collector sea urchin, Tripneustes gratilla were investigated in a captive laboratory condition. The study was conducted by setting different levels of temperatures $\left(24^{\circ} \mathrm{C}\right.$ to $\left.36^{\circ} \mathrm{C}\right)$ and 
salinities (38\%o to $23 \%$ ). Within the range of temperature from 24 to $36^{\circ} \mathrm{C}$ and at $32 \%$ salinity, hatching and normal larval rates, and SAI values were highest at 24 and $27^{\circ} \mathrm{C}$. The highest hatching and normal larval rates were found at 35 and $38 \%$ within the salinity range of $23-38 \%$; however, SAI value was the highest at $26 \%$. The results of the experiments in each level of temperature $(24,27$ and $\left.30^{\circ} \mathrm{C}\right)$ with each salinity $(32,35$ and $38 \%$ ) indicated interactive effects of temperature and salinity, and within the experimental protocols of $24^{\circ} \mathrm{C}$ at $38 \%$ gave an optimal combination for highest hatching and survival of $T$. gratilla. The findings obtained from the present research would not only be immensely helpful towards the understanding of the suitable temperature-salinity interactions but also facilitate the development of captive breeding, larval raising and mass seed production of this high-valued sea urchin for commercial aquaculture.

Keywords: T. gratilla; temperature; salinity; hatching rate; normal larval rate; survival activity index.

\section{INTRODUCTION}

Among the environmental factors, seawater temperature and salinity are the critical abiotic factors that have the greatest effect on the whole life history of fishes [1,2] and echinoderm sea urchins (see the references below). In particular, at embryonic and early larval stages, water temperature and salinity independently and/or interactively affect survival by influencing the physiological states $[3,4]$. Among the abiotic factors, temperature and salinity are considered as the most vital factors in embryonic development of purple sea urchin, Paracentrous lividus [5]. Besides that, several former studies showed that the salinity has significant effects on survival, embryonic and larval development of sea urchins $[6,7,8]$. Kashenko [9] stated that increasing salinities have affected the time needed for embryonic development of Echinocardium cordatum in the same temperature. Metaxas [7] observed that decreasing salinities slowed larval development of Echinometra lucunter. Allen and Pechenik [10] reported that fertilization envelope of eggs rarely rises and even successfully fertilized eggs do not cleave after presenting to low salinity seawater. In regards of larvae, the range of salinity tolerance can be broader or narrower than their adults. The larvae of Atlantic sea urchin (Echinometra lucunter) are more sensitive to salinities and can tolerate narrower ranges of salinities than those of their adults [7]. The low salinity condition reduces feeding rate, decreases growth performance and consequently limits the size of ectoderms [9]. Decreasing salinity caused the reduction of viability and also yielded mass mortality of adult sea urchin, Lytechinus variegatus at Florida [11].

Early life stages of broadcast-spawning marine invertebrates from the phylum Echinodermata has been used to assess the effects of increasing surface temperature on marine biota
$[12,13]$. Over the past century, the fertilization of eggs of echinoderms was well categorized due to use in comparative embryological research [14]. Early life stages of echinoderms, especially sea urchins are also recognized to be highly sensitive to a wide range of environmental contaminants and stressors [15], and thus making them as an ideal state for assessing impacts of climatechange. In addition, the egg fertilization and larval development of sea urchin have previously been shown only to happen within distinct temperature ranges for some species $[16,17]$. So, the ocean warming largely affects these life stages.

The heart-shaped irregular sea urchin, Echinocardium cordatum (Pennant) occurs in temperate latitudes of the Pacific and the Atlantic $[18,19]$ and also the Peter Great Bay in Russian waters [20]. According to Kashenko [21], the lower limit of salinity tolerance of the adult heart-shaped sea urchin was $28 \%$, which corresponded to its regular habitat in such a depth of the marine ecosystem. The animals those were placed on firm substrate without having any opportunity to burrow, could even survive for 3 days within the salinity levels of 28$33 \%$, but all of them were dead at the end of the $8^{\text {th }}$ day, however, upon a salinity drop to $20 \%$ or lower, all of them were dead within a day.

From the fertilization to formation of the pluteus larval stage, the early development of heartshaped sea urchin has been described in detail, however, the times needed for reaching different developmental stages varied to some extent according to the studies of different authors [22]. The sequence of the developmental events of the sea urchin, inhabiting the Vostok Bay in the Sea of Japan, was determined by Kashenko [23]. In discrepancy to the bottom-dwelling adult sea urchin, the early development occurs in the water column. During the monsoon weather, the suddenly fluctuating temperature and salinity of 
sea water could terribly impact on the larvae of marine invertebrates.

To determine the survival rates and development of larvae of marine benthic invertebrates, the importance of temperature and salinity have not been completely characterized. Several previous studies have done on different invertebrate taxa and found that deviations in temperature and salinity from ambient values had caused increased mortality and/or delayed development (e.g. barnacles: [24,25]; bivalves: [26,27]; echinoderms: [6]; polychaetes: [28,29]), while others observed that salinity is not an important factor in determining larval survival [30-32].

In addition, data on environmental control for the improvement of the hatching rate and larval development will potentially be applicable to high density intensive egg management systems for mass larval production. Therefore, our study aimed to contribute information on the suitable egg incubation and early larval rearing environment for the development of sea urchin aquaculture technology as well as to obtain appropriate information on sea urchin, $T$. gratilla early life history. This study examined the rates of hatching and normal larval development, and the survival activity index (SAI) of $T$. gratilla larvae by rearing under various temperatures and salinities after the blastula stage. SAI values can be used as a practical indicator to evaluate the larval tolerance to varying environmental conditions $[33,34]$.

\section{MATERIALS AND METHODS}

\subsection{Sample Collection and Conditioning}

Around 56 matured adults of $T$. gratilla, weighing from 165 to $256 \mathrm{~g}$ in live weight and 84 to 122 $\mathrm{mm}$ in test diameter, were collected from Bum Bum Island $\left(5^{\circ} 66^{\prime} \mathrm{N}, 100^{\circ} 28^{\prime} \mathrm{E}\right)$, Semporna, Sabah, Eastern Malaysia (Fig. 1) at low tide during their natural breeding season from January to May, 2016. The specimens were then transferred with aerated plastic bucket to the laboratory of the Institute of Bioscience, Universiti Putra Malaysia (UPM), where they were maintained in an outdoor tank with flowthrough seawater and fed with a diet of brown macroalgae (Sargassum sp.).

\subsection{Spawning and Fertilization}

Most of the urchins were used for this experiment within a week after collection. The Aristotle's lantern was removed from the healthy specimens by using scissors and forceps, and then rinsed thoroughly with sterilized filtered sea water (SFSW), which was first prepared on Advantec qualitative filter paper (Toyo Roshi Kaisha, Japan) and then autoclaved 10 minutes for sterilization. Gametes were obtained from each

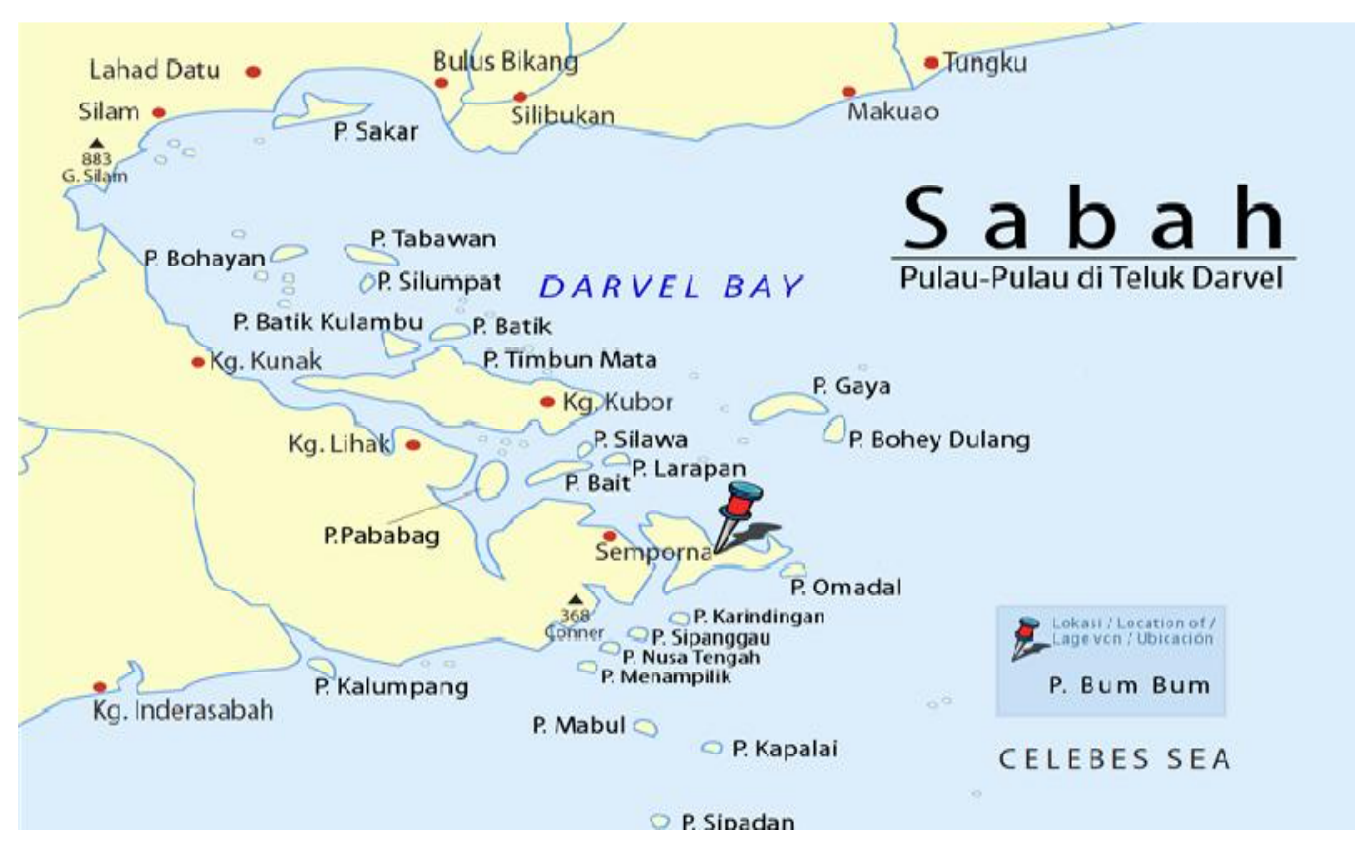

Fig. 1. Sampling area of T. gratilla in Pulau Bum Bum (Bum Bum Island), Semporna, Sabah, Eastern Malaysia 
sea urchin after the injection with $2-3 \mathrm{ml}$ of $0.5 \mathrm{M}$ $\mathrm{KCl}$ solution into the coelomic cavity. Eggs were collected by inverting the gravid female urchin on a glass beaker filled with SFSW. "Dry" sperm (in the most concentrated form of sperm, released at the time of spawning using the above $\mathrm{KCl}$ method) were then pipetted off the genital pores and kept in a refrigerator at $4-5^{\circ} \mathrm{C}$ for not more than 3-4 hours, while the eggs were placed in a glass beaker containing SFSW and maintained at normal room temperature $\left(28-30^{\circ} \mathrm{C}\right)$.

Fertilization was done by adding two drops of diluted sperm into a petri dish containing $15 \mathrm{~mL}$ egg suspension (300 eggs $/ \mathrm{mL})$. Sperm concentration was maintained at $10^{-5}$ dilution of "Dry" sperm $[35,36]$. The sperm was kept with eggs for 5-10 minutes and then sperm in excess was cleaned by 3-4 successive washes with SFSW [35,36]. Three replicate fertilization experiments were performed using fresh gametes from new specimens in each time.

\subsection{Experimental Procedure}

In this experiment, near about one thousand fertilized eggs from the incubation containers, were transferred to $1 \mathrm{~L}$ beakers filled with 800 $\mathrm{mL}$ of filtered seawater and maintained at the experimental temperatures and salinities. In regards of the single factor experiment studying the effect of temperature, treatments were adjusted to $24,27,30,33$, and $36^{\circ} \mathrm{C}$ with a salinity level of $32 \%$ o (approximately equal to the spawning salinity at the Laboratory of Marine Biotechnology, Institute of Bioscience, UPM). For salinity trial, the treatments were adjusted to 23 , $26,29,32,35$ and $38 \%$ with a temperature of $30^{\circ} \mathrm{C}$ (approximately equal to the spawning temperature at the same laboratory). In respect of the combined two-factor treatment with water temperature and salinity, three different temperatures of 24,27 and $30^{\circ} \mathrm{C}$ were combined with three different salinities of 32,35 and $38 \%$ o for incubation. The experimental treatments were conducted in three biological replicates, corresponding to the three different spawning trials. All single and two-factor experiments were carried out with three replicates for each. Water was not changed and aeration was not provided in beakers during the experiment. Each experimental temperature was maintained in a water bath using heaters (Seapalex300, Nisso, Japan) and chillers (DSHP-4-WC, Aqua Logic Inc., USA). Each salinity trial was maintained by using mixtures of artificial sea salt powder (Sea life, Marine Tech Co. Ltd, Japan) and groundwater (salinity level $\leq 0.2 \%$ ). The dissolved oxygen contents in the treated water were measured at the start of egg stocking and after removing all dead larvae; the values (mean \pm SD; $n=3$ ) for these stages were $83.76 \pm 4.20 \%$ and $83.10 \pm 1.50 \%$, respectively.

\subsection{Data Calculation}

In regards to the estimation of larval survival activity index (SAl), all the surviving gastrula larvae after hatching were used to obtain the SAI value in the same beakers of the incubation trials. From one day after hatching (DAH), all the dead larvae and larvae with morphological abnormalities were carefully removed daily from each beaker using a pipette and their number was counted. The hatching rate, normal larval rate, and SAI were calculated by the following equations [37]:

$$
\begin{aligned}
& \text { Hatching rate }(\%)=\frac{N}{N+U E} \times 100 \\
& \text { Normal larval rate }(\%)=\frac{N-M}{N+U E} \times 100 \\
& \mathrm{SAI}=\frac{\sum_{i=1}^{k}(N-h i) X i}{N}
\end{aligned}
$$

Where,

$N=$ Total number of larvae,

$U E=$ The number of unhatched eggs at $14 \mathrm{~h}$ after the start of hatching,

$M=$ The number of morphologically abnormal larvae,

$h i=$ The accumulated mortality by the $i$-th day and

$k=$ The number of days elapsed until total larval mortality under fasting conditions.

\subsection{Statistical Analyses}

The percentage data are presented as mean \pm SD $(N=3)$ in the figures and tables. For statistical analysis, all percentage data from each experiment were arcsine transformed [36]. Hatching rates, normal larval rates, and SAI values obtained from the single factor experiments were statistically analyzed by oneway analysis of variance (ANOVA), while the values from the two-factor experiment were analyzed, using a two-way ANOVA. Where significant differences $(p<0.05)$ were found using Levene's test for homogeneity of variance in any experiment by one-or two-way ANOVA, the values of one-factor experiments were tested 
post hoc by the Tukey test $(p<0.05)$. If a significant interaction $(p<0.05)$ between temperature and salinity by two-way ANOVA was observed, the simple main effect in each factor was then analyzed to determine the individual mean differences by the Tukey test $(p<0.05)$. All statistical analyses were carried out using the computerized SPSS version 20 (IBM SPSS Inc., Chicago, USA) for Windows 10.

\section{RESULTS}

In the single factor experimental treatment with temperatures (conducted in the laboratory at $32 \%$ salinity), the significantly highest $(p<0.05)$ rates of hatching, normal larval development and SAI of T. gratilla were obtained at $24^{\circ} \mathrm{C}$ and $27^{\circ} \mathrm{C}$ than those at the spawning temperature $\left(30^{\circ} \mathrm{C}\right)$, while the values were the lowest at $36^{\circ} \mathrm{C}$ (Table 1).

While examining the effects of salinity in the single factor experiment (conducted at $30^{\circ} \mathrm{C}$ temperature), salinities $35 \%$ and $38 \%$, among the treatments, exhibited the significantly highest $(p<0.05)$ hatching success of $84.97 \pm 4.07 \%$ and $96.39 \pm 2.68 \%$ and the normal larval survival of
$78.91 \pm 3.78 \%$ and $92.97 \pm 2.59 \%$, respectively. However, the hatching and normal larval rates of $46.44-58.85 \%$, and $10.68-43.9 \%$ at the salinity levels of $23-32 \%$, respectively were considerably low compared to the above values (Table 2). Furthermore, the SAl value was significantly higher $(p<0.05)$ at $26 \%(17.28 \pm 0.50 \%)$ than other salinities tested $(\leq 11.70 \pm 0.68 \%)$.

In the two-factor experiment, the temperatures $\left(24,27\right.$, and $\left.30^{\circ} \mathrm{C}\right)$ and salinities $(32,35$, and $38 \%$ ) that showed higher hatching and normal larval rates in the single factor experiment, were selected for further study. In this trial, the highest rates of hatching $(100.0 \pm 0.0 \%)$ and normal larval development $(99.7 \pm 0.5 \%)$ were observed at $24^{\circ} \mathrm{C}$ and $38 \%$, among the combinations of the two factors evaluated (i.e. temperature and salinity) (Figs. 2 and 3).

Hatching began within $6 \mathrm{~h}$ post-fertilization in all water temperatures where $>95 \%$ of eggs were hatched by $18 \mathrm{~h}$ at $27^{\circ} \mathrm{C}$ and $30^{\circ} \mathrm{C}$, while $>95 \%$ of the eggs hatched by $24 \mathrm{~h}$ at $24^{\circ} \mathrm{C}$ (Fig. 4). A significant interaction $(p<0.05)$ was observed between water temperature and salinity on the hatching of $T$. gratilla (Fig. 4).

Table 1. Hatching rate, normal larval rate (NLR), and survival activity index (SAl) of the tropical sea urchin ( $T$. gratilla) at different experimental temperatures in the laboratory at $32 \%$ salinity

\begin{tabular}{llll}
\hline $\begin{array}{l}\text { Water } \\
\text { temperature }\end{array}$ & $\begin{array}{l}\text { Hatching rate } \\
\text { (HR \%) }\end{array}$ & $\begin{array}{l}\text { Normal larval rate } \\
\text { (NLR \%) }\end{array}$ & $\begin{array}{l}\text { Survival activity index } \\
\text { (SAI) }\end{array}$ \\
\hline $36^{\circ} \mathrm{C}$ & $18.92 \pm 6.25^{\mathrm{a}}(13.50-25.75)$ & $1.95 \pm 0.64^{\mathrm{a}}(1.39-2.65)$ & $1.38 \pm 0.45^{\mathrm{a}}(0.98-1.87)$ \\
$33^{\circ} \mathrm{C}$ & $43.17 \pm 8.13^{\mathrm{b}}(35.5-51.75)$ & $29.00 \pm 5.48^{\mathrm{b}}(23.85-34.77)$ & $10.20 \pm 1.93^{\mathrm{b}}(8.38-9.98)$ \\
$30^{\circ} \mathrm{C}$ & $76.86 \pm 8.73^{\mathrm{c}}(69.55-86.52)$ & $69.98 \pm 7.94^{\mathrm{c}}(63.33-78.78)$ & $11.80 \pm 1.34^{\mathrm{b}}(10.68-13.28)$ \\
$27^{\circ} \mathrm{C}$ & $96.06 \pm 2.95^{\mathrm{d}}(92.75-98.55)$ & $89.15 \pm 2.78^{\mathrm{d}}(86.08-91.44)$ & $19.31 \pm 0.60^{\mathrm{c}}(18.65-19.81)$ \\
$24^{\circ} \mathrm{C}$ & $98.80 \pm 1.23^{\mathrm{d}}(97.55-100)$ & $96.03 \pm 1.19^{\mathrm{d}}(95.2-97.2)$ & $23.41 \pm 0.29^{\mathrm{d}}(23.2-23.7)$ \\
\hline \multicolumn{4}{c}{ All values represent mean \pm SD with ranges in parentheses. Mean values in the same column with different } \\
\multicolumn{4}{c}{ superscripts are significantly different $(p<0.05)$}
\end{tabular}

Table 2. Hatching rate, normal larval rate (NLR), and survival activity index (SAI) of the tropical sea urchin ( $T$. gratilla) under different salinities in the laboratory at $30^{\circ} \mathrm{C}$ temperature

\begin{tabular}{clll}
\hline Salinity & $\begin{array}{l}\text { Hatching rate } \\
\text { (HR \%) }\end{array}$ & $\begin{array}{l}\text { Normal larval rate } \\
\text { (NLR \%) }\end{array}$ & $\begin{array}{l}\text { Survival activity index } \\
\text { (SAI) }\end{array}$ \\
\hline $38 \% 0$ & $96.39 \pm 2.68^{\mathrm{d}}(93.55-98.88)$ & $92.97 \pm 2.59^{\mathrm{f}}(90.22-95.36)$ & $8.57 \pm 0.23^{\mathrm{b}}(8.31-8.79)$ \\
$35 \% 0$ & $84.97 \pm 4.07^{\mathrm{C}}(80.54-88.55)$ & $78.91 \pm 3.78^{\mathrm{e}}(74.79-82.23)$ & $9.80 \pm 0.47^{\mathrm{c}}(9.34-10.28)$ \\
$32 \% 0$ & $58.34 \pm 2.47^{\mathrm{b}}(55.65-58.85)$ & $42.31 \pm 1.79^{\mathrm{d}}(40.36-43.90)$ & $5.55 \pm 0.23^{\mathrm{a}}(5.29-5.79)$ \\
$29 \% 0$ & $49.20 \pm 2.88^{\mathrm{a}}(46.52-48.48)$ & $34.87 \pm 2.04^{\mathrm{c}}(32.96-37.02)$ & $11.70 \pm 0.68^{\mathrm{d}}(11.05-12.41)$ \\
$26 \%$ & $44.68 \pm 1.96^{\mathrm{a}}(44.55-46.65)$ & $20.92 \pm 0.92^{\mathrm{b}}(20.86-21.84)$ & $17.28 \pm 0.50^{\mathrm{e}}(16.92-17.72)$ \\
$23 \% \circ$ & $49.23 \pm 3.09^{\mathrm{a}}(46.44-52.56)$ & $11.36 \pm 0.70^{\mathrm{a}}(10.68-12.09)$ & $8.97 \pm 0.56^{\mathrm{b}}(8.46-9.57)$ \\
\hline \multicolumn{3}{c}{ All values represent mean \pm SD with ranges in parentheses. Mean values in the same column with different } \\
\multicolumn{3}{c}{ superscripts are significantly different $(p<0.05)$}
\end{tabular}




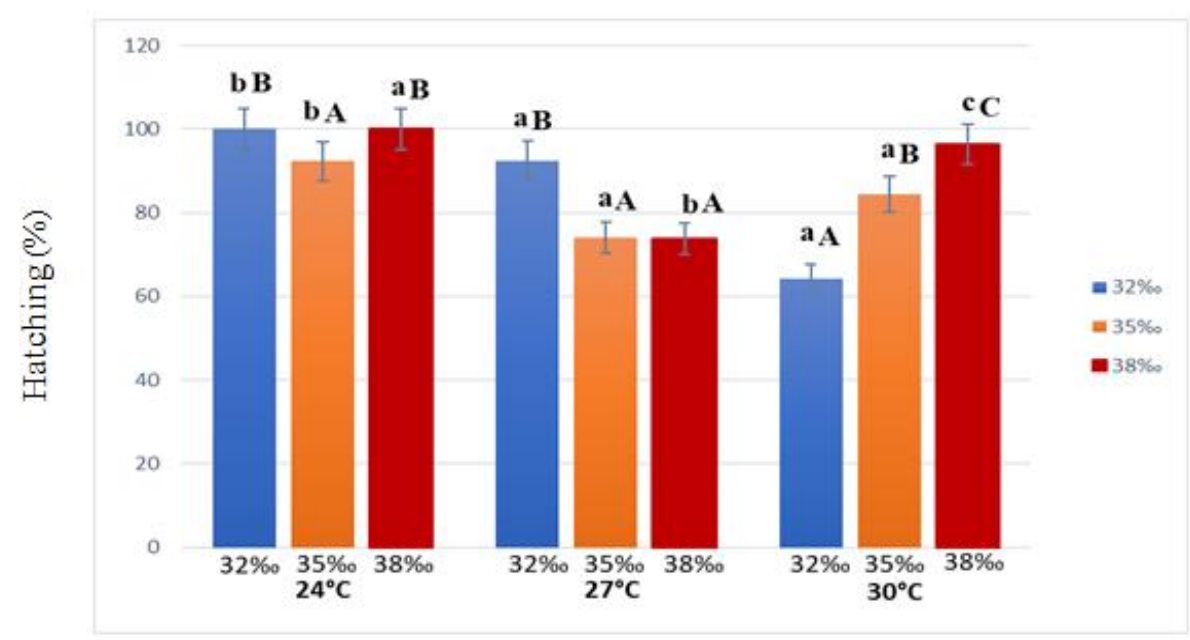

Salinity $(\%)$ and temperature $\left({ }^{\circ} \mathrm{C}\right)$

Fig. 2. Combined effects of temperature and salinity on the mean hatching (\%) of T. gratilla. The bar on each diagram indicates standard deviation ( $\pm S D$ ); $n=3$. The letters $a, b$ and $c$ show significant differences within the same temperature $(p<0.05)$, while A, B, C indicate significant differences among temperatures within the same salinity $(p<0.05)$

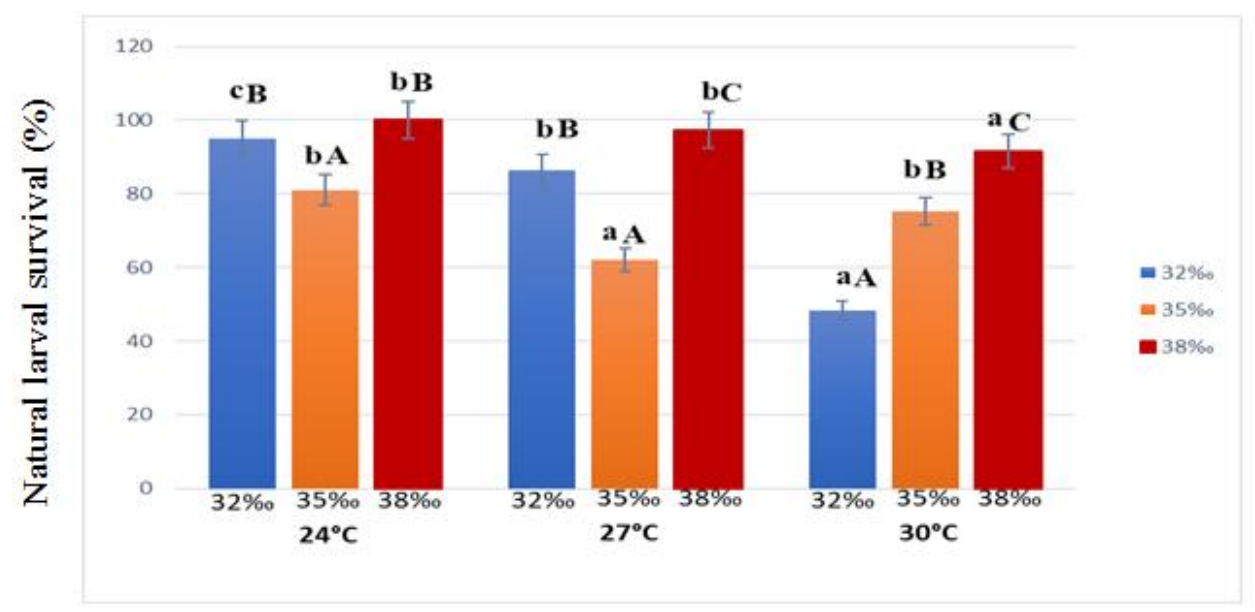

Salinity $(\%)$ and temperature $\left({ }^{\circ} \mathrm{C}\right)$

Fig. 3. Combined effects of temperature and salinity on the mean natural larval survival (\%) of T. gratilla. The bar on each diagram indicates standard deviation ( $\pm S D) ; n=3$. The letters $a, b$ and $c$ show significant differences within the same temperature $(p<0.05)$, while A, B and C indicate significant differences among temperatures within the same salinity $(p<0.05)$

Table 3. The effects of combinations of salinity and temperature on the hatching rates of the sea urchin, T. gratilla by two-way ANOVA

\begin{tabular}{llllll}
\hline $\begin{array}{l}\text { Sources of } \\
\text { variation }\end{array}$ & SS & $\boldsymbol{d f}$ & MS & F-ratio & $\begin{array}{l}\mathbf{5 \%} \text { F-limit (or the } \\
\text { tabulated value) }\end{array}$ \\
\hline Temp (T) & 2 & 1645.1283 & 822.56413 & 60.53 & $<0.0001$ \\
Salinity (S) & 2 & 112.61616 & 56.308078 & 4.14 & 0.0331 \\
T x S & 4 & 2196.4201 & 549.10503 & 40.41 & $<0.0001$ \\
\hline
\end{tabular}

SS = Sum of squares; $d f=$ degree of freedom; MS = mean of square 

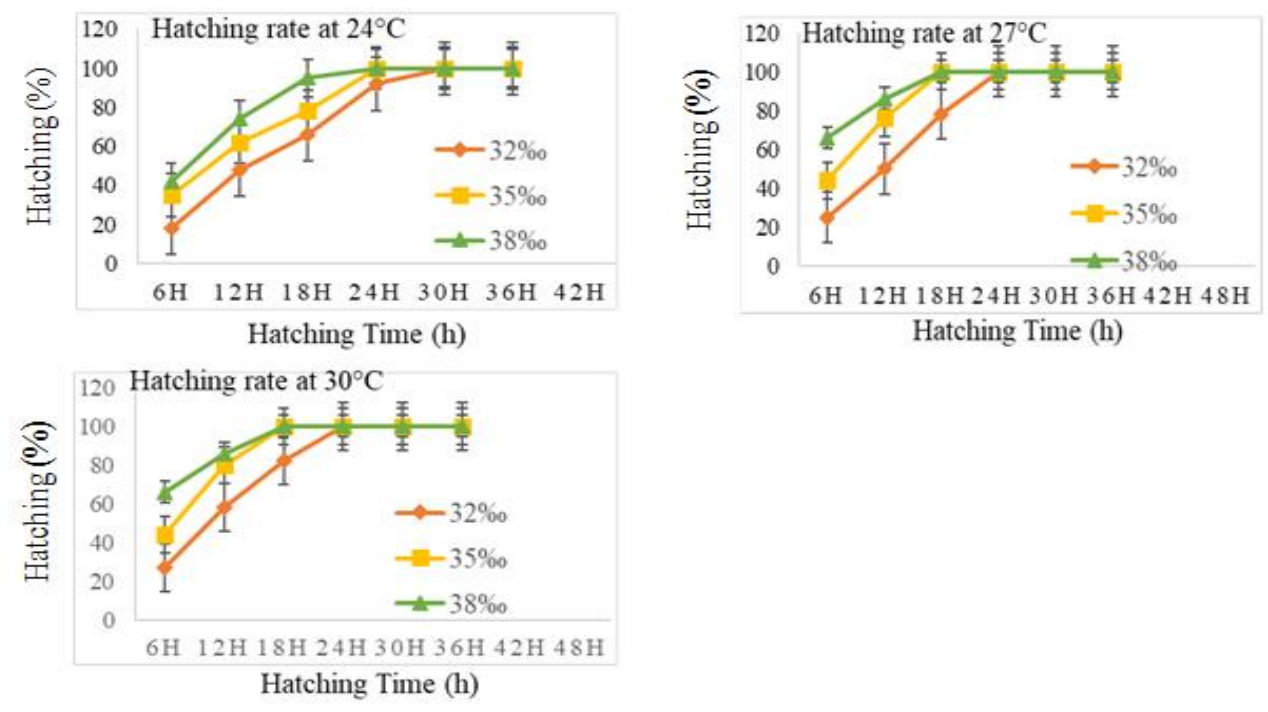

Fig. 4. Comparisons of hatching success of $T$. gratilla eggs at different temperatures under different salinity treatments

Table 4. The effects of combinations of salinity and temperature on the normal larval rates of the sea urchin, $T$. gratilla by two-way ANOVA

\begin{tabular}{llllll}
\hline $\begin{array}{l}\text { Sources of } \\
\text { variation }\end{array}$ & SS & df & MS & F-ratio & $\begin{array}{l}\mathbf{5 \%} \text { F-limit (or the } \\
\text { tabulated value) }\end{array}$ \\
\hline Temp (T) & 2 & 1785.4678 & 892.73388 & 71.45 & $<0.0001$ \\
Salinity (S) & 2 & 2767.0298 & 1383.5149 & 110.73 & $<0.0001$ \\
T x S & 4 & 2559.6509 & 639.91273 & 51.21 & $<0.0001$ \\
\hline \multicolumn{5}{l}{ SS = Sum of squares; $d f=$ degree of freedom; MS = mean of square }
\end{tabular}

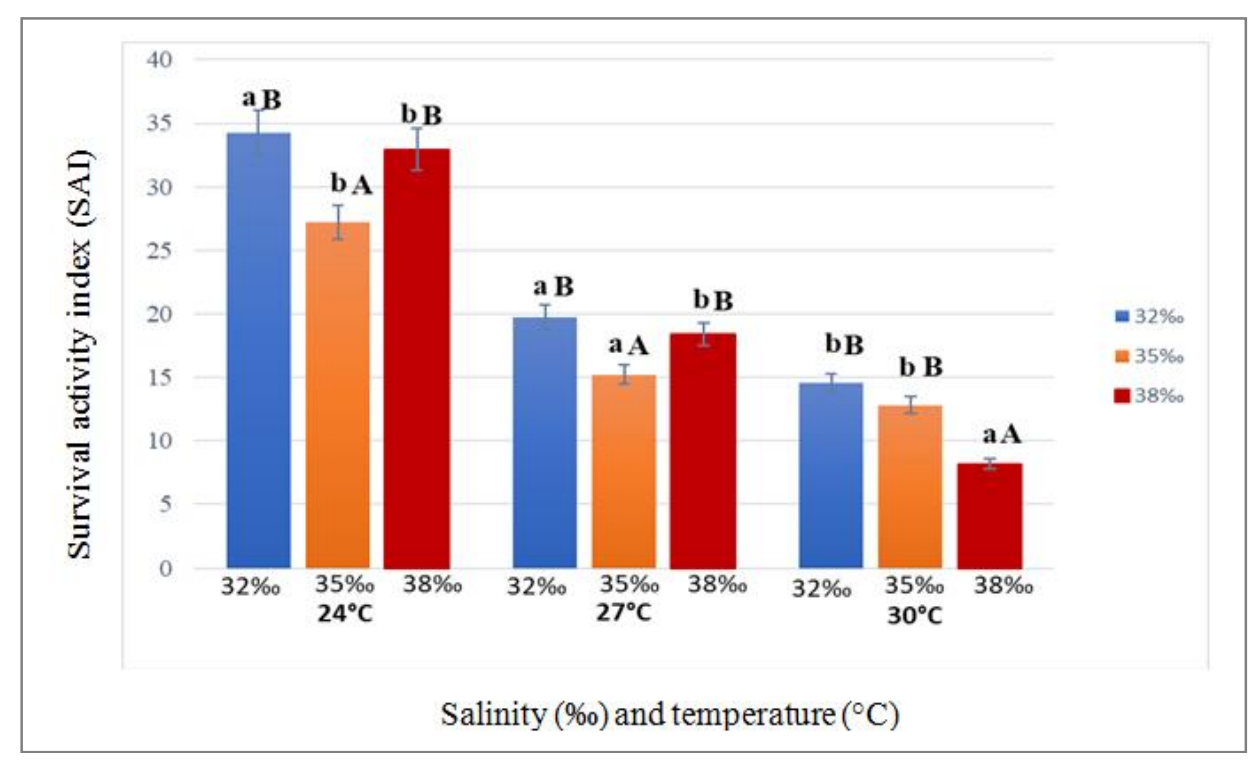

Fig. 5. Comparison of survival activity index (SAl) of $T$. gratilla larvae under different combinations of temperature and salinity. The bar indicates standard deviation ( $\pm S D$ ); $n=3$. The letters $a, b$ and $c$ show significant differences within the same temperature $(p<0.05)$, while $A$, $B$ and $C$ indicate significant differences among temperatures within the same salinity $(p<0.05)$ 
Table 5. The effects of combinations of salinity and temperature on the SAl of the sea urchin, T. gratilla by two-way ANOVA

\begin{tabular}{llllll}
\hline $\begin{array}{l}\text { Sources of } \\
\text { variation }\end{array}$ & SS & $\boldsymbol{d f}$ & MS & F-ratio & $\begin{array}{l}\mathbf{5} \% \text { F-limit (or the } \\
\text { tabulated value) }\end{array}$ \\
\hline Temp (T) & 2 & 1876.2774 & 938.13872 & 228.75 & $<0.0001$ \\
Salinity (S) & 2 & 133.4977 & 66.748848 & 16.28 & $<0.0001$ \\
Tx S & 4 & 112.40877 & 28.102193 & 6.85 & 0.0016 \\
\hline
\end{tabular}

SS = Sum of squares; $d f=$ degree of freedom; MS = mean of square

Temperature, salinity and their combined trials in this study confirmed to have significant effects ( $p$ $<0.05$ ) on the hatching and normal larval rates by two-way ANOVA (Table 3 and 4). Temperature exclusively $(p<0.000)$ and combinations of both temperature and salinity have significantly $(p=0.032)$ affected the SAI values (Table 5 ). Furthermore, there were no significant $(p>0.05)$ differences recognized at $24^{\circ} \mathrm{C}$ among the examined salinities by simple main effect analysis (Fig. 5).

\section{DISCUSSION}

It has been established that larvae of many sea urchin species are stenohaline and their survival and growth are greatly affected by salinity changes $[10,38,39]$. In this experiment, the effects of environmental factors on the fertilization and embryonic development of the collector sea urchin within the ranges of temperature and the salinity were chosen that correspond to those in various habitats of this species, e.g., the surface and bottom water layers of the Indo-Pacific Ocean. Our research demonstrated that the fertilization was successful in $T$. gratilla within a wide range of temperatures from 24 to $36^{\circ} \mathrm{C}$ that met the temperature requirements of this species to start spawning. A decrease in salinity depressed the fertilization ability of the collector sea urchin, especially in combination with the lowest $\left(24^{\circ} \mathrm{C}\right)$ and the highest $\left(36^{\circ} \mathrm{C}\right)$ temperatures, while a salinity of $23 \%$ inhibited it. However, fertilization was still possible in this minimal salinity (i.e., 23\%o) that matched with the lower limit of resistance of adult individuals of the collector sea urchin $[40,41]$. A similar phenomenon was also recorded in other echinoderms, such as cucumaria sea cucumber (Eupentacta fraudatrix), and sea stars (Asterias amurensis and Asterina pecinifera), although fertilization in these species was still observed at the minimum salinity levels $(20 \%$ and $18 \%$, respectively), which were lower than in $T$. gratilla $[42,43,44,45]$. However, in the present study, the fertilization success of $T$. gratilla was normally occurred at the temperatures from $24^{\circ} \mathrm{C}$ to $36^{\circ} \mathrm{C}$ within a salinity range from $23 \%$ to $38 \%$.
After the completion of blastopore stage of many fish species including Pacific Bluefin tuna (PBT) Thunnus orientalis [46], eggs are reported to have a higher tolerance to variations in environmental conditions compared to the blastomere stage [45,47]. Though the effects of a sudden changes of environmental conditions on hatching and normal larval rates in each development stage of fertilized eggs of $T$. gratilla have not been detailed in the literature, the effects may be similar to the observed results in the congeneric scombrid species of PBT [48]. In a view for mass seed production of $T$. gratilla, the collection of blastula stage eggs from a sea urchin bloodstock tank or a net cage is considered to be difficult to enable various procedures (eliminate impurities, sterilization, rinse, removal of unfertilized eggs, counting, etc.) for egg management as $T$. gratilla eggs have a fast development speed. Therefore, the fertilized eggs in the blastula stage, which are assumed to have low environmental tolerance may be unsuitable for egg management procedures, and the obtained results using Kupffer's vesicledisappearance stage of fertilized eggs would be more appropriate for various procedures towards the mass seed production of $T$. gratilla; however, this requires further investigations.

The optimal temperature ranges for hatching success and normal larval development rate were reported to be $23-26^{\circ} \mathrm{C}$ in yellow fin tuna (YFT) by Harada et al. [49], who obtained the highest hatching rate $(\geq 78 \%$, including dead and deformed larvae) and normal larval development rate $(\geq 58 \%)$ at a temperature range of 26.4 $27.8^{\circ} \mathrm{C}$ without information on salinity. Although it is not possible to elucidate correctly the cause of this difference, it may be attributable to differences in the experimental methods, e.g., differences in the fertilization process (artificial and natural), stability of the treatment temperature, whether the beakers were aerated or not, the egg development stage at each treatment, and differences between the brood fish groups used (genetic, age, dietary factors, etc.). Regarding larval survival, the SAI values in our study were significantly higher at $24^{\circ} \mathrm{C}$ and 
$27^{\circ} \mathrm{C}$ than those in other higher temperature groups. The results of this study are similar to that obtained by Harada et al. [49].

In the present study, optimal range of hatching and normal larval development rates were observed within the salinity levels of $35 \% 0-38 \%$ and was higher than that of the brood stock spawning. The previously observed positive effect of higher salinity during YFT embryonic development was related to the prevention of their sedimentation and better dispersion of floating eggs by increased buoyancy in the higher salinity water $[50,51]$, which has a positive effect on the survival of embryos and larvae [52]. Adverse effects on hatching and normal larval development in the lower salinity water has been reported in many other species $[53,54,55]$. The salinity in the YFT's main habitats (fishing grounds) and spawning grounds in the Pacific and the Indian oceans have been known to range from 34.8 to $35.0 \%$ and 35.3 to $35.7 \%$, respectively $[56,57]$. These ranges are similar to the optimum range observed in this study.

In experiment with the combined effect of temperature and salinity, the hatching rate and normal larval rate of $T$. gratilla at $38 \%$ salinity consistently showed the highest values $(96.39 \pm 2.68 \%$ and $92.97 \pm 2.59 \%$, respectively) compared to those at $32 \%$ o $(58.34 \pm 2.47 \%$ and $42.31 \pm 1.79 \%$, respectively) and at $35 \%$ $(84.97 \pm 4.07 \%$ and $78.91 \pm 3.78 \%$, respectively) regardless of the temperature treatment. The hatching rate $(98.80 \pm 1.23 \%)$ and the normal larval rate $(96.03 \pm 1.19 \%)$ at $24^{\circ} \mathrm{C}$ was significantly higher than that $(18.92 \pm 6.25 \%$ and $1.95 \pm 0.64 \%$ ) at $30^{\circ} \mathrm{C}$. On the other hand, the SAI at $23^{\circ} \mathrm{C}$ showed the highest values in all the tested salinities. These results revealed that within the ranges tested, the combination of $38 \%$ and $24^{\circ} \mathrm{C}$ was found to be the most effective and optimal water temperature and salinity combination for improving/increasing the hatching and survival rates of the fertilized eggs of $T$. gratilla. Furthermore, the sensitivity to the temperature and salinity during the embryonic period and that for hatching larvae of $T$. gratilla seem to differ among each life stage. That is, in the embryonic period, combined effects of temperature and salinity occurred, while hatching larvae were affected solely by temperature (that is, larval stage had relatively higher salinity tolerance than the embryonic stage). In regards of the $T$. gratilla seed production, these results (preference for low water temperature) may be applied to the development of technology to reduce occurrences of mass mortality during the early stage of sea urchin larvae [58].

Although the highest survival rate and smallest number of abnormal forms were recorded at $24^{\circ} \mathrm{C}$, larvae reached to the hatching (gastrula) stage at normal salinity, while at $30^{\circ} \mathrm{C}$ to $36^{\circ} \mathrm{C}$, they developed very slowly and only attained to the blastula stage. A decrease in temperature combined with a decrease of salinity delayed development and upon an increase of temperature, the range of salinity in which the larvae developed normally was narrowed. Thus, free swimming blastulae of the sea urchin, $T$. gratilla have adaptive abilities that enabled larvae to survive and develop for several days in the unstable condition of the surface water layer in a wide range of temperatures (from $24^{\circ} \mathrm{C}$ up to $36^{\circ} \mathrm{C}$ ) and salinity (from $38 \%$ to $23 \%$ ). A sharp increase in the resistance of larvae at the stage of the free-swimming blastula with the variation of the environmental parameters was also the characteristics of other echinoderm species [42, $44,45,59]$. Significant resistance of larvae to a decrease in salinity at various stages of development could be higher than adult individuals, which are also the characteristics of other invertebrates and most likely related to ecological features upon passing these stages $[60,61,62,63]$.

\section{CONCLUSION}

From the present findings, it could be concluded that the significantly higher hatching and normal larval rate, and survival of fasting larvae after hatching (survival activity index, SAl) were observed at the lower experimental temperature and higher salinity, respectively. In respect of sea urchin hatchery production, the interactions of these environmental factors can be considered not only as the standard parameter for induced breeding and larval rearing of $T$. gratilla, but also will facilitate us to develop the appropriate techniques for mass seed production and commercial aquaculture of this important sea urchin fishery to a greater extent.

\section{DISCLAIMER}

The products used for this research are commonly and predominantly used products in our area of research and country. There is absolutely no conflict of interest between the authors and producers of the products because we do not intend to use these products as an avenue for any litigation but for the advancement of knowledge. Also, the research was not funded 
by the producing company rather it was funded by personal efforts of the authors.

\section{ETHICAL APPROVAL}

As per international standard, written ethical permission has been collected and preserved by the author(s).

\section{ACKNOWLEDGEMENT}

The authors would like to extend sincere thanks and appreciations to the Ministry of Science, Technology and Innovation (MOSTI), Malaysia for providing financial supports through Universiti Putra Malaysia (UPM) under the "Science Fund" grant vide Project No. 04-01-04-SF2227 (Vote No. 5450794) for successfully completing this research.

\section{COMPETING INTERESTS}

Authors have declared that no competing interests exist.

\section{REFERENCES}

1. Fielder DS, Bardsley WJ, Allan GL, Pankhurst PM. The effects of salinity and temperature on growth and survival of Australian snapper, Pagrus auratus larvae. Aquaculture. 2005;250:201-214.

2. Ostrowski AD, Watanabe WO, Montgomery FP, Rezek TC, Shafer TH, Morris JA. Jr. Effects of salinity and temperature on the growth, survival, whole body osmolality, and expression of $\mathrm{Na}+/ \mathrm{K}+$ ATPase mRNA in red porgy (Pagrus pagrus) larvae. Aquaculture. 2011;314:193-201.

3. Blaxter JHS. Pattern and variety in development. In: Hoar WS, Randall DJ (Eds). Fish Physiology. Academic Press, New York. 1988;1-58.

4. Rombough PJ. The effects of temperature on embryonic and larval development. In: Wood CM, McDonald DG (Eds.). Global warming: implications for freshwater and marine fish, Society for experimental biology seminar series 61. Cambridge University Press, Cambridge. 1997;177224.

5. Bressan M, Marin M, Brunetti R. Influence of temperature and salinity on embryonic development of Paracentrotus lividus (Lmk, 1816). Hydrobiologia. 1995;304:175184.
6. Roller RA, Stickle WB. Effects of temperature and salinity acclimation of adults on larval survival, physiology and early development of Lytechinus variegatus (Echinodermata: Echinoidea). Mar Biol. 1993;116:583-591.

7. Metaxas A. The effects of salinity on larval survival and development in the sea urchin Echinometra lucunter. Invertebr Reprod Dev. 1998;34(2-3):323-330.

8. Forcucci D, Lawrence JM. Effect of low salinity on the activity, feeding, growth and absorption efficiency of Luidia clathrata (Echinodermata: Asteroidea). Mar Biol. 1986;92:315-321.

9. Kashenko SD. Adaptive responses of embryos and larvae of the heart-shaped sea urchin Echinocardium cordatum to temperature and salinity changes. Russ $\mathrm{J}$ Mar Biol. 2007;33:381-390.

10. Allen JD, Pechenik JA. Understanding the effects of low salinity on fertilization success and early development in the sand dollar Echinarachnius parma. Biol Bull. 2010;218:189-199.

11. Lawrence JM. The effect of temperaturesalinity combinations on functional wellbeing of adult Lytechinus variegatus (Lamarck) (Echinodermata, Echinoidea). J Exp Mar Biol Ecol. 1975;18:271-275.

12. Byrne $M$, Soars NA, Ho MA, Wong $E$, McElroy D. Selvakumaraswamy $P$, Dworjanyn SA, Davis AR. Fertilization in a suite of coastal marine invertebrates from SE Australia is robust to near-future ocean warming and acidification. Mar Biol. 2010; 157:2061-2069.

13. Byrne M. Global change ecotoxicology: Identification of early life history bottlenecks in marine invertebrates, variable species responses and variable experimental approaches. Mar Environ Res. 2012;76:3-15.

14. Hart MW. Life history evolution and comparative developmental biology of echinoderms. Evol Dev. 2002;4(1):6271.

15. Dinnel, PA, Link JM, Stober QJ, Letourneau MW, Roberts WE. Comparative sensitivity of sea urchin sperm bioassays to metals and pesticides. Arch Environ Contam Toxicol. 1989;18: 748-755.

16. Mita M, Hino A, Yasumasu I. Effect of temperature on interaction between eggs and spermatozoa of sea urchin. Biol Bull. 1984;166:68-77. 
17. Sewell MA, Young CM. Temperature limits of fertilization and early development in the tropical sea urchin Echinometra lucunter. J Exp Mar Biol Ecol. 1999;236: 291-305.

18. Féral JP, Poulin E, Oubelkheir K. Geographic and Genetic Differentiation of Echinocardium cordatum (Pennant) - the Current State of a Complex Question: The Status of Echinocardium fenauxi (Péquignat). In: Mooi R, Telford M. (Eds.). Echinoderms: San Francisco, Rotterdam: Balkema. 1998;647-649.

19. Osanai K. Handling Japanese Sea Urchins and Their Embryos, The Sea Urchin embryo, Berlin: Springer-Verlag. 1975;2640.

20. Baranova Zl. Phylum Echinodermata, Zhivotnye $i$ rasteniya zaliva Petra Velikogo (Animals and Plants of Peter the Great Bay), Leningrad: Nauka. 1976;114-120.

21. Kashenko SD. Resistance of the heart sea urchin Echinocardium cordatum (Echinoidea: Spatangoida) to extreme environmental changes. Biol Morya. 2006a;32(6):447-449.

22. Kasyanov VL, Kryuchkova GA, Kulikova VA, Medvedeva LA. Larvae of Sea Urchins (Morphology, Physiology, Behaviour), Lichinki morskikh dvustvorchatykh mollyuskov i iglokozhikh (Larvae of Marine Bivalves and Echinoderm), Moscow: Nauka. 1983;108-154.

23. Kasyanov VL, Medvedeva LA, Yakovlev SN, Yakovlev YuM. The heart-shaped sea urchin Echinocardium cordatum, Razmnozhenie iglokozhikh i dvustvorchatykh mollyuskov (Reproduction of Echinoderms and Bivalves), Moscow: Nauka. 1980;64-71.

24. Anil AC, Kurian J. Influence of food concentration temperature and salinity on the larval development of Bolamus amphitrite. Mar Biol. 1996;127:115-124.

25. Crisp DJ, Costlow JD. The tolerance of developing cirripede embryos to salinity and temperature. Oikaos. 1963;14:22-34.

26. Bayne BL. Growth and the delay of metamorphosis of the larvae of Mytilus edulis (L). Ophelia. 1965;2:1-47.

27. Calabrese A, Davis HC. Tolerances and recruitments of embryos and larvae of bilave molluscs. Helgoland. Meeresunt. 1970;20:553-564.

28. Gray JS. The effects of salinity, temperature and mercury on mortality of the trochophore larvae of Serpula vermicularis L. (Annelida: Polychaeta). J Exp Mar Biol Ecol. 1976;23:127-134.

29. Richmond CE, Woodin SA. Short-term fluctuations in salinity: effects on planktonic invertebrate larvae. Mar Ecol Prog Ser. 1996;133:167-177.

30. Young AM, Hazlett TL. The effect of salinity and temperature on the larval development of Clibanarius vittatus (Bosc) (Crustacea: Decapoda: Diogenidae). J Exp Mar Biol Ecol. 1978;34:131-141.

31. Cameron RA, Scotte EF, Roy JB, Eric HD. The oral-aboral axis of a sea urchin embryo is specified by first cleavage. Development. 1989;106(4):641-647.

32. Pechenik JA. Environmental influences on larval survival and development. In: Giese $A C$, Pearse JS (Eds.). Reproduction of marine invertebrates. New York: Academic Press. 1987;551-608.

33. Mushiake K, Fujimoto $\mathrm{H}$, Shimma $\mathrm{H}$. A trial of evaluation of activity in yellowtail, Seriola quinqueradiata larvae. Suisanzoshoku. 1993;41:339-344. (in Japanese with English abstract)

34. Wang Y, Li L, Cui G, Lu W. Ontogenesis from embryo to juvenile and salinity tolerance of Japanese devil stinger Inimicus japonicus during early life stage. Springerplus. 2013;2:289-301.

35. Rahman MA. Uehara T, Aslan LM. Comparative viability and growth of hybrids between two sympatric species of sea urchins (Genus Echinometra) in Okinawa. Aquaculture. 2000;183(1-2):45-56.

36. Rahman MA, Uehara T, Lawrence JM. Growth and heterosis of hybrids of two closely related species of Pacific sea urchins (genus Echinometra) in Okinawa. Aquaculture. 2005;245:121-133.

37. Shimma H, Tsujigado A. Some biochemical quality of bred scorpaenoid fish, Sebastiscus marmoratus, and activities of their larvae. Bulletin of the National Research Institute of Aquaculture. 1981;2:11-20.

38. Cowart DA, Ulrich PN, Miller DC, Marsh AG. Salinity sensitivity of early embryos of Antarctic sea urchin Sterechimus neumayeri. Polar Biol. 2009;32:435-441.

39. Parvez MS, Rahman M, Yusoff FM, Arshad A, Lee S-G. Influence of temperature variation on embryonic and early larval development of a commercially important tropical sea urchin Tripneustes gratilla (Linnaeus, 1758). Indian J Fish. 2018;65(2):72-81. 
40. Parvez MS, Rahman M, Yusoff FM, Arshad A, Lee SG. Salinity effects on the development of embryos and larvae of a high-valued sea urchin, Tripneustes gratilla (Linnaeus, 1758). J Environ Biol. 2018;39: 785-794.

41. Shimabukuro S. Tripneustes gratilla (sea urchin). In: Shokita S, Kakazu K, Tomomi A, Toma T, Yamaguchi M (Eds.). Aquaculture in Tropical Areas. Midori Shobo Co. Ltd. Tokyo. 1991;313-328.

42. Kashenko SD. Combined effect of temperature and salinity on the development of the holothurian Eupentacta fraudatrix. Biol Morya. 2000;26(3):182187.

43. Kashenko SD, The reaction of the starfish Asterias amurensis and Patiria pectinifera (Asteroidea) from Vostok Bay (Sea of Japan) to a salinity decrease. Biol Morya. 2003;29(2);127-131.

44. Kashenko SD. Responses of embryos and larvae of the starfish Asterias amurensis to changes in temperature and salinity. Biol Morya. 2005;31(5):344-351.

45. Kashenko SD. The combined effect of temperature and salinity on development of the sea star Asterina pectinifera. Biol. Morya. 2006b;32(1):43-49.

46. Miyashita S, Tanaka $Y$, Sawada $Y$, Murata O, Hattori N, Takii K, Mukai Y, Kumai H. Embryonic development and effects of water temperature on hatching of bluefin tuna, Thunnus thynnus. Suisanzoshoku. 2000;48:199-200. (in Japanese with English abstract)

47. Saranchova OL, Flyachinskaya LP. The influence of salinity on early ontogeny of the mussel Mytilus edulis and the starfish Asterias rubens from the White Sea. Biol. Morya. 2001;27(2):110-116.

48. Fairbridge RW, Itie T, Berry J. North Sea, The Encyclopedia of Oceanography. Leningrad: Gidrometeoizdat. 1974;446453.

49. Harada $\mathrm{T}$, Miyashita $\mathrm{S}$, Yoneshima $\mathrm{H}$. Effect of water temperature on yellowfin tuna hatching. Mem Fac Agric Kinki Univ. 1980;13:29-32.

50. Battaglene SC, Talbot RB. Effects of salinity and aeration on survival of and initial swim bladder inflation in larval Australian bass. Prog Fish Cult. 1993;55: 35-39.

51. Margulies EH, Cooper GM, Asimenos G, Thomas DJ, Dewey CN, Siepel A, Birney E, Keefe D, Schwartz AS, Hou M, et al.
Analyses of deep mammalian sequence alignments and constraint predictions for $1 \%$ of the human genome. Genome Res. 2007; 17:760-774.

52. Hart RP, Purser GJ. Effects of salinity and temperature on eggs and yolk sac larvae of the greenback flounder (Rhombosolea tapirina Günter, 1862). Aquaculture. 1995; 136:221-230.

53. Young PS, Duenãs CE. Salinity tolerance of fertilized eggs and yolk-sac larvae of the rabbit fish Siganus guttatus (Bloch). Aquaculture. 1993;112:363-377.

54. Haddy JA, Pankhurst NW. The effects of salinity on reproductive development, plasma steroid levels, fertilization and egg survival in black bream Acanthopagrus butcheri. Aquaculture. 2004;188:115131.

55. Gracia-López V, Kiewek-Martínez M, Maldonado-García M. Effects of temperature and salinity on artificially reproduced eggs and larvae of leopard grouper Mycteroperca rosacea. Aquaculture. 2004;237:485-498.

56. Cho KD, Kim YA, Park SW, Kim JC, Park MS. Relationship between the catches of tuna and oceanographic conditions in the South-East Pacific. Bull Korean Fish Soc. 1987;20:360-369. (in Korean with English abstract)

57. Song LM, Zhang $Y, X u$ LX, Jiang WX, Wang JQ. Environmental preferences of longlining for yellowfin tuna (Thunnus albacares) in the tropical high seas of the Indian Ocean. Fish Oceangr. 2008;17:239253.

58. Sawada Y, Okada T, Miyashita S, Murata $\mathrm{O}$, Kumai $\mathrm{H}$. Completion of the Pacific bluefin tuna Thunnus orientalis (Temmincket Schlegel) life cycle. Fish Sci. 2005;36:413-421.

59. Kashenko SD. Effects of temperature and salinity on the early development of the Japanese sea cucumber (Trepang) Stichopus japonicas. Biol Morya. 1998; 24(2):103-107.

60. Kashenko SD. Adaptatsii k temperature i opresneniyu nekotorykh vidov khitonov zaliva Petra Velikogo na raznykh stadiyakh ontogeneza (The temperature and freshening adaptations of some chiton species of Peter the Great Bay at various stages of Ontogenesis): Abstract of Cand Sci (Biol.) Dissertation, Vladivostok: Inst Biol Morya Dal Vost Otd. AN SSSR; 1987. 
61. Yaroslavtseva LM. Naidenko TK, Sergeeva EP, Yaroslavtsev PV, Response to freshening of blue mussel from the Sea of Japan at various stages of development. Biol Morya. 1986;4:40-47.

62. Nagabhushanam R, Gopala K, Murti K. Effect of salinity on the developmental stages of Chiton granoradiatus Leloup. J Anim Physiol Anim Nutr. 1967;14(1):162165.

63. Kashenko SD. The effect of freshening on development of Far East Trepang. Biol Morya. 1992;(3-4):43-52.

(c) 2020 Parvez et al.; This is an Open Access article distributed under the terms of the Creative Commons Attribution License (http://creativecommons.org/licenses/by/4.0), which permits unrestricted use, distribution, and reproduction in any medium, provided the original work is properly cited.

Peer-review history:

The peer review history for this paper can be accessed here: http://www. sdiarticle4.com/review-history/57654 